\title{
REGIMEN JURIDICO DE LA CONSERVACION, PROTECCION Y REHABILITACION DE CONJUNTOS DE CARACTER HISTORICO
}

34: $711.52: 930.26$

por

Sebastián Grau Avila y Margarita Alós Martín

Técnicos de Administración General de la Corporación Metropolitana de Barcelona

SUMARIO: I. PRESENTACION.-II. LA PROPIEDAD CULTURAL COMO PROPIEDAD ESPECIAL.-III. LAS COMISIONES PROVINCIALES DE DEFENSA DEL PATRIMONIO HISTORICOARTISTICO.-IV. EL REGIMEN JURIDICO DE LOS CONJUNTOS HISTORICOS Y DE LOS MONUMENTOS HISTORICOARTISTICOS.-V. EL PLANEAMIENTO ESPECIAL. TEORIA GENERAL. LOS PLANES ESPECIALES DE PROTECCION.VI. LAS COMUNIDADES AUTONOMAS. ENTES PREAUTONOMICOS Y PROTECCION DEL PATRIMONIO. - VII. COMPETENCIAS DE LA ADMINISTRACION CENTRAL Y LOCAL EN LA PROTECCION DEL PATRIMONIO URBANO.-VIII. EL CATALOGO URBANISTICO DE BIENES CULTURALES.-IX. EL PLAN ESPECIAL DE REFORMA INTERIOR DEL ALBAICIN (GRANADA).- $X$. LA LEGISLACION SOBRE EL PATRIMONIO CULTURAL.-XI. LAS LICENCIAS URBANISTICAS Y LA PROTECCION DEL PATRIMONIO CULTURAL.-XII. FISCALIDAD Y PATRIMONIO ARTISTICO.-XIII. CONCLUSIONES. 


\section{PRESENTACION}

Esta crónica pretende ser una breve síntesis expositiva de los principales puntos tratados en la «Semana de Estudios sobre el Régimen Jurídico de la Conservación, Protección y Rehabilitación de Conjuntos Urbanos de Carácter Histórico", celebrada en Granada durante el mes de mayo último y organizada por la Delegación Interprovincial de Granada del Instituto de Estudios de Administración Local y el Departamento de Derecho Administrativo de su Universidad.

El método a seguir va a ser una breve presentación de los conferenciantes que han intervenido, por orden cronológico, y una exposición de los principales aspectos planteados en las charlas, sin pretender llegar al grado de profundización que alcanzaron los coloquios, por la evidente dificultad de recoger todas las intervenciones.

Con estas notas se pretende confeccionar un breve catálogo de los problemas suscitados por la legislación vigente en materia de protección del patrimonio cultural.

Debe aprovecharse la oportunidad para felicitar públicamente a los conferenciantes que han intervenido en las sesiones por el alto nivel doctrinal demostrado en el tratamiento de los problemas suscitados, y especialmente a los Profesores don Eduardo RocA Roca y don Jesús Mellado González, Director y Coordinador, respectivamente, de la Semana, así como a todo el personal de la Delegación en Granada del IEAL, por la cordialidad con que han atendido a los participantes.

\section{LA PROPIEDAD CULTURAL COMO PROPIEDAD ESPECIAL.}

Por don José Sánchez Faba, Magistrado excedente y Presidente de la Diputación Provincial de Granada.

En esta conferencia se trataba de encuadrar jurídicamente la: propiedad cultural dentro de una $u$ otra de las distintas fórmulas $o$ instituciones que significan regímenes especiales o diferenciados del derecho de propiedad.

Se esbozó de entrada una aproximación al concepto de propiedad cultural, refiriéndose a la participación de toda la sociedad. 
en su configuración, a los objetivos de mejora del medio ambiente y de la calidad de vida y a las principales causas de la destrucción del patrimonio cultural, señalando entre ellas la superpoblación, las transformaciones urbanas propiciadas por las técnicas urbanisticas, la contaminación, la proletarización de los viejos centros urbanos y la congelación de alquileres.

Se entra en la exposición de la necesidad sentida en la mayoría de países de establecer una nueva regulación del derecho de propiedad y, dentro de él, una serie de regímenes jurídicos diferenciados en razón del conflicto planteado entre la configuración de este derecho en su forma tradicional y los intereses superiores de la sociedad.

Centrándose concretamente en la propiedad cultural, se refiere el conferenciante a su configuración como un tipo especial de propiedad que suele llevar aparejadas una serie de cargas impuestas al propietario.

Se analizan los elementos de la propiedad histórico-artística; en sentido subjetivo, podrán ser titulares tanto las personas públicas como las privadas; en cuanto al elemento objetivo, podrá recaer sobre cualquier clase de bienes dotados de un determinado valor; y en cuanto a su naturaleza jurídica, se centra la cuestión en determinar si se trata de una servidumbre, de limitación de dominio o de bienes demaniales.

La teoría de la servidumbre es la tesis histórica para explicar la naturaleza del régimen específico de los bienes que integran el patrimonio histórico-artístico. Se trata de impedir que los propietarios dispongan libremente de la cosa; sin embargo, es indudable que las servidumbres se ajustan a las situaciones en que nacen obligaciones definitivas, pero no cuando se imponen cargas positivas a los propietarios.

GARCÍA DE ENTERRÍA se inclina por la naturaleza del régimen de este tipo de propiedad como meras limitaciones de dominio, limitaciones que definen el contenido normal del derecho de propiedad. Se tratará de un régimen estatutario permanente.

Una última teoría se inclina por atribuir a este patrimonio las características de los bienes demaniales. Se trata de bienes privados cuya situación jurídica se aproxima al dominio público. En esta corriente se incluirían García-Trevijano y Martín Mateo. Sin embargo, la crítica de esta postura se centra en que la demania- 
lidad implica la posibilidad de desafectación, lo cual no parece admisible en el patrimonio cultural.

En definitiva, para el conferenciante se trata de un tipo especial de propiedad, llamada a estar caracterizada por un régimen específico de intervención administrativa dirigida a la conservación del objeto. En consecuencia, se sostiene que tal carácter viene conferido por la propia naturaleza y por las circunstancias objetivas de los bienes y nunca por la mera catalogación o inventario de los bienes. Existirá propiedad especial siempre que se aprecie un interés especial en el objeto que se trata de proteger.

Finalmente, el ponente expone el contenido objetivo de esta propiedad especial, diciendo que puede abarcar el patrimonio cultural y el patrimonio natural, extendiéndose a edificios, conjuntos, su entorno, bienes muebles, parajes culturales y obras de cine o fotografía.

El diálogo se centra en los siguientes aspectos:

1. Carácter expansivo e indeterminado del concepto de monumento.

2. La configuración de este derecho de propiedad especial en los planes y en las normas urbanísticas.

\section{LAS COMISIONES PROVINCIALES DE DEFENSA DEL PATRIMONIO HISTORICO-ARTISTICO}

Por don Vicente González Barberán, Consejero provincial de Bellas Artes y Delegado provincial del Ministerio de Cultura en Granada.

Esta charla está dirigida a exponer las vivencias personales y experiencias vividas por el conferenciante, que reúne la condición de Consejero provincial de Bellas Artes y la de Delegado provincial del Ministerio de Cultura. Se exponen los antecedentes de las actuales Comisiones Provinciales de Defensa del Patrimonio Histórico-Artístico, creadas por Decreto de 22 de octubre de 1970, y se hace referencia a las antiguas Comisiones de Monumentos, las cuales carecían virtualmente de capacidad para imponer sus decisiones. 
Entra la charla en una exposición pormenorizada de diversos casos vividos, de los cuales cabe extraer como común denominador las siguientes conclusiones:

1. ${ }^{\mathrm{a}} \quad$ Las Comisiones Provinciales de Defensa del Patrimonio Histórico-Artístico actúan prescindiendo de criterios urbanísticos y de acuerdo con unos planteamientos personales o subjetivos de sus miembros. Por ello, las líneas de actuación pueden ser radicalmente distintas si comparamos unas Provincias con otras.

2. ${ }^{\mathrm{a}} \quad$ Los Ayuntamientos, en la actualidad, suelen respetar y cumplir la legislación del Patrimonio histórico-artístico en cuanto a la necesidad de autorización de las autoridades del Ministerio de Cultura en actuaciones que afecten a monumentos declarados o conjuntos urbanos.

\section{EL REGIMEN JURIDICO DE LOS CONJUNTOS HISTORICOS Y DE LOS MONUMENTOS HISTORICO-ARTISTICOS}

Por don Manuel Pallarés Moreno, Secretario provincial del Ministerio de Cultura y Profesor adjunto de Derecho Administrativo de la Universidad de Granada.

Se inicia la charla con una exposición de las formas clásicas de intervención de la Administración en la actividad o en la esfera de los particulares, llegándose a la conclusión de que la intervención en materias de Patrimonio histórico-artístico no encaja exactamente en ninguna de las tres formas tradicionales.

La intervención directa (servicio público) sería aquella en la que la Administración pública se hace cargo del bien mediante su compra o expropiación.

La intervención indirecta, a través de la actividad de policía, se encauza mediante técnicas de limitación previa catalogación; por último, la actividad de fomento, como forma de intervención indirecta, se articula mediante las técnicas de las subvenciones, exenciones y bonificaciones fiscales.

Seguidamente se entra en la determinación de lo que sea el régimen jurídico del Patrimonio histórico-artístico como aquel conjunto de normas jurídicas definidoras de unas notas peculiares 
que lo diferencian del régimen jurídico general. Este régimen vendría a aplicarse a los bienes concretos mediante el acto de catalogación.

Se hace referencia a continuación a cuáles son las normas jurídicas que regulan específicamente el Patrimonio histórico-artístico y a aquellas otras no específicas que pueden incidir ocasionalmente en esta materia. Dentro del primer grupo estarían:

- La Ley de Espacios naturales protegidos, de 2 de mayo de 1975, y su Reglamento de 4 de marzo de 1977.

- La Ley del Patrimonio histórico-artístico, de 13 de mayo de 1933, y su Reglamento de 16 de abril de 1936.

- El Decreto que regula los Monumentos provinciales y loca. les, de 22 de julio de 1958.

- Las Instrucciones para la defensa de los Conjuntos histórico-artísticos, de 20 de noviembre de 1964.

En el segundo grupo podríamos incluir, a los meros efectos enunciativos, las normas que regulan la expropiación forzosa por razones de interés histórico y las normas sobre zonas de interés turístico.

Se entró a continuación en el análisis de los distintos elementos definidores del Patrimonio histórico-artístico, y al efecto se distinguió entre:

a) Bienes que lo integran: Se trata de bienes muebles o inmuebles, de cierto interés intrínseco. Los criterios para la definición de tal interés son amplios y discrecionales.

b) Titulares de los bienes: Pueden ser todas las personas jurídicas, tanto públicas como privadas, y tanto las que tienen los bienes como propietarios, como los que son nuevos poseedores $o$ usufructuarios.

c) Acto declarativo del carácter histórico-artístico del bien o catalogación: Es el que define el régimen jurídico aplicable.

En cuanto a la catalogación, se estudian los siguientes elementos:

a) Sujeto: Debe ser el sujeto capaz y el órgano competente, siendo éste el Ministerio de Cultura, a través de la Dirección de Bellas Artes, Archivos y Bibliotecas. Se facilita el siguiente organigrama: 
ADMINISTRACION CENTRAL

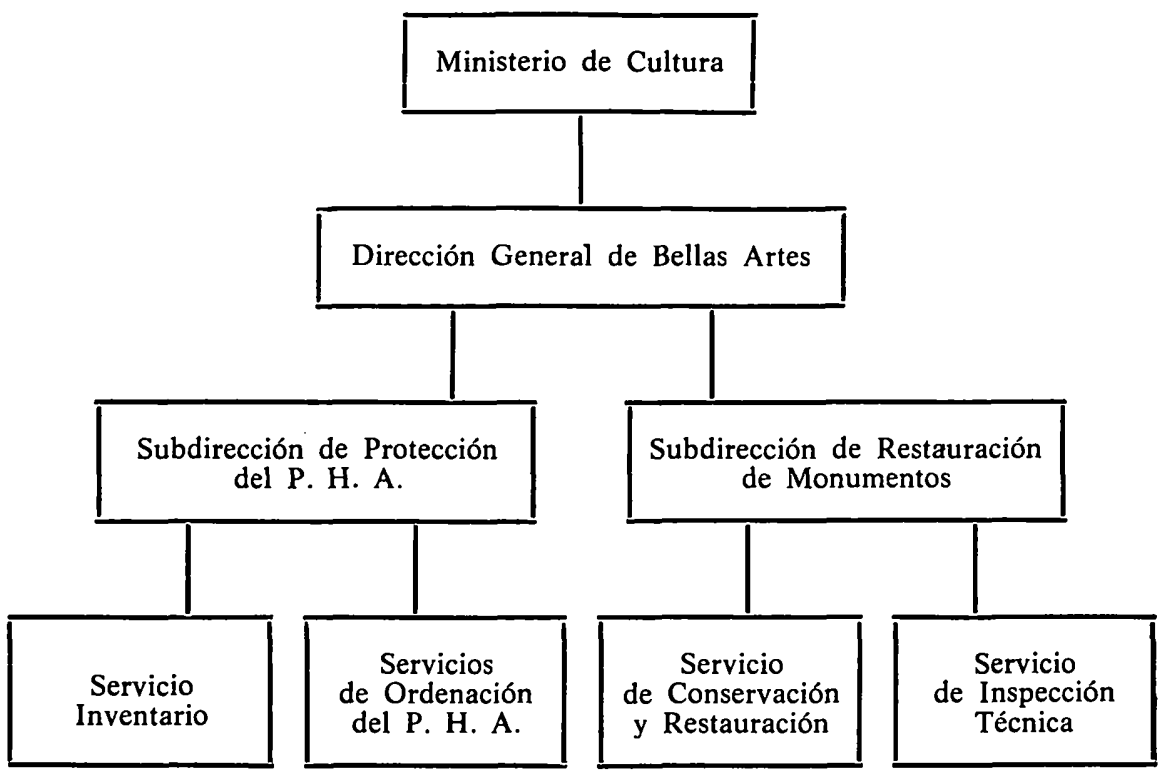

\section{ADMINISTRACION PERIFERICA}

- Delegados provinciales de Cultura.

- Comisiones provinciales de Defensa del P. H. A.

- Comisiones mixtas.

- Comisarios del P. H. A.

- Patronatos específicos.

b) Objeto: El objeto de la catalogación consiste en una declaración de voluntad de la Administración. Se trata de un acto administrativo de carácter negocial, fundamentalmente discrecional y limitativo de la esfera de derechos del particular.

c) Efectos genéricos: El bien catalogado se convierte en algo público (publicatio), pasando a ser tutelado y defendido por el Estado. La catalogación significa, pues, una habilitación legal para establecer limitaciones en razón del bien que se trata de proteger.

d) Efectos específicos:

- Función de cuidado y tutela.

- Derecho de tanteo a favor del Estado.

- Posibilidad de acudir a la expropiación. 
- Obligación para el Municipio de velar por la conservación de los bienes catalogados de su término municipal.

- Obligación de la Administración de contribuir económicamente a la restauración.

- En cuanto a los particulares, se producen una serie de limitaciones detalladas en los artículos 19, 23, 24 y 26 de la Ley de 1933.

e) Forma: La catalogación debe regirse por los principios generales de procedimiento establecidos en la Ley de Procedimiento administrativo. El artículo 16 de la Ley de 1933 y el 19 de su Reglamento prevén un procedimiento normal y otro abreviado.

f) Medidas provisionales: El artículo 17 de la Ley prohíbe la realización de obras desde el inicio del procedimiento.

g) Fin: La tutela, conservación, mejora y protección del bien.

V. EL PLANEAMIENTO ESPECIAL. TEORIA GENERAL. LOS PLANES ESPECIALES DE PROTECCION

Por don Luciano Parejo Alfonso, Abogado, Profesor adjunto de Derecho Administrativo de la Universidad Complutense de Madrid.

Se aborda en primer lugar el encuadramiento de los Planes Especiales dentro del sistema general de planeamiento establecido por la Ley del Suelo. La Ley de 1956 distinguía claramente los Planes Territoriales de los Especiales; en la reforma de 1975 sólo existe el planeamiento territorial que engloba los Planes Especiales. Estos Planes son los que abordan el territorio desde una perspectiva no global ni integrada, sino sectorial y reducida a un sector determinado de problemas; tienen, pues, funciones muy amplias, que pueden abarcar desde la resolución de problemas muy concretos hasta el planeamiento de un sector del territorio.

Se resalta la importancia del Plan Especial como instrumento de desarrollo del Plan General, especialmente el suelo urbano.

Así pues, el objeto es el elemento definidor de la esencia de los Planes Especiales.

Para encuadrarlos en el sistema de planeamiento de la Ley debe partirse de la división entre el subsistema directivo, que abarca el 
Plan Nacional y los Planes Directores Territoriales de Coordinación, y el subsistema operativo, que integra los llamados Planes Municipales. Pues bien, el Plan Especial se inserta en la cascada lógica de progresiva concreción del contenido del derecho de propiedad (art. 6. ${ }^{\circ}$ LS).

Sin embargo, el artículo 17 de la Ley del Suelo permite la existencia de Planes Especiales aun sin planeamiento general. Luego estas figuras aparecen como instrumentos polivalentes, situados al margen del desarrollo ordinario del planeamiento general, de donde se deduce la diversidad de su contenido potencial.

Así pues, los Planes Especiales pueden ser:

a) Planes derivados que traen causa de otro anterior para:

- Ejecución directa de previsiones de Planes Directores Territoriales de Coordinación.

- Ordenación del territorio impuesta por Plan General o Normas complementarias o subsidiarias.

b) Planes independientes, que no supongan la existencia de Plan integral previo (art. 76, 3, R. Planeamiento). El conferenciante cree que se trata de una previsión del Reglamento contraria a la Ley del Suelo y, por tanto, nula.

En definitiva, se define el Plan Especial por las siguientes características:

- Es un instrumento sin ubicación fija en el sistema de planeamiento.

- Es un instrumento derivado.

- Es un instrumento no necesario.

- Es un instrumento de función y contenido diversos.

Seguidamente el conferenciante propone una tipología de los Planes Especiales, distinguiendo el criterio del objeto del plan del criterio de la figura de planeamiento superior que desarrolló el Plan Especial. Combinando ambos criterios se formula la siguiente clasificación:

1. a) Planes especiales de ordenación derivados de un planeamiento previo.

b) Planes especiales operativos e independientes de un ordenamiento anterior. 
2. a) Planes especiales de protección.

b) Planes especiales de reforma interior $\mathrm{y} / \mathrm{o}$ saneamiento.

3. a) Planes ejecutivos de desarrollo de infraestructuras básicas.

b) Planes ejecutivos de desarrollo de la estructura general y orgánica del territorio.

Centrándonos en los Planes especiales de reforma interior y saneamiento, puede decirse que suponen un acercamiento a las figuras de ordenación integral del territorio, recogiendo en el suelo urbano la dialéctica Plan General-Plan Parcial.

Concluye este apartado el conferenciante exponiendo su conocida tesis en cuanto al contenido y determinaciones de los Planes especiales de reforma interior en el sentido de que deben ser las mismas, incluso en lo relativo a estándares, que las exigidas para los Planes Parciales en suelo urbanizable programado, en virtud de la remisión del artículo 77, 3, del Reglamento de Planeamiento.

En una segunda parte de su conferencia se abordan por el Profesor PaREJo los problemas específicos de los Planes especiales de protección. Habla de las metas generales del planeamiento en cuanto a la coordinación entre crecimiento y calidad de vida; se refiere a la visión desarrollista a ultranza aplicada por los Planes de Desarrollo Económico y Social, si bien a partir de 1974 el IV Plan de Desarrollo pasa a dar una mayor importancia a los criterios sociales y de racionalización de la planificación del territorio, en coordinación con el espíritu de la reforma de la Ley del Suelo de 1975.

En el suelo urbano se trata específicamente de revitalizar y conservar los centros urbanos para mejorar el nivel de calidad de vida y del medio ambiente. Este criterio es recogido en el artículo 45 de la Constitución de 1978.

Las técnicas impuestas por la legislación vigente en orden a la mejora de la calidad de vida darían lugar a la aparición de dos regímenes legales representados por la legislación de protección del Patrimonio histórico-artístico y por el régimen urbanístico de la Ley del Suelo. Esta última legislación aborda los problemas desde el punto de vista de la mayor racionalidad en los aprove- 
chamientos del territorio y en la ponderación de todos los elementos que globalmente inciden en el mismo. Las formas utilizadas serían:

- La coordinación con la pianificación económica.

- La vinculación de las planificaciones sectoriales al planeamiento regional superior.

- El planeamiento urbanístico como síntesis de la ordenación de todo el territorio español.

La articulación de estas técnicas se concreta en un marco legal a desarrollar a través del planeamiento:

- Concretamente, el Plan General Municipal de Ordenación, contemplado como la figura básica de coordinación de las medidas de protección de la calidad de la vida y del medio ambiente urbano (art. 12 LS).

- El Plan Especial sería así concebido con la función de complementar el planeamiento integral superior.

A la hora de ver la eficacia práctica de la figura de los Planes Especiales se tropieza con muchas dificultades por:

- La inexistencia de estándares legales en suelo urbano.

- La consagración para el suelo urbano de un estatuto del derecho de propiedad distinto del previsto para el suelo urbanizable.

- La radical inadecuación de las técnicas de gestión al suelo urbano.

- La dificultad en la definición de polígonos y unidades de actuación.

Seguidamente se entra en el difícil problema de la determinación de lo que debe entenderse por vinculaciones singulares del derecho de propiedad a través del planeamiento y en relación con el derecho a indemnización por reducción del aprovechamiento urbanístico. Se expone que procede indemnización en todos los casos en que unas cargas individualizables y diferenciadas se atribuyan a unos propietarios determinados con trato desigual respecto de los otros y sin que dichas cargas puedan ser objeto de reparcelación. 
Este principio lo articula el conferenciante al tema general de la responsabilidad de la Administración por daños a administrados que no deban ser soportados y como resultado de un funcionamiento normal de los servicios públicos, sin que pueda decirse que el simple cambio en el estatuto que regula la propiedad lleve aparejada la indemnización. Esta nacerá cuando el propietario haya patrimonializado la potencialidad edificatoria permitida por el planeamiento anterior que se sustituye.

\section{LAS COMUNIDADES AUTONOMAS. ENTES PREAUTONOMICOS Y PROTECCION DEL PATRIMONIO}

Por don Luis Felipe Aparicio, Director general de Política Territorial e Infraestructura de la Junta de Andalucia.

En esta conferencia el Profesor esboza unas ideas de carácter teórico sobre el contenido de las corrientes ideológicas más importantes en materia urbanística y su relación con las distintas políticas municipales de suelo.

Inicia la intervención con unas referencias a la legislación vigente, empezando por la Constitución y siguiendo por las leyes concretas que la complementan, refiriéndose seguidamente a la distribución de competencia entre el Estado, a través de la Comisión Interministerial del Medio Ambiente (CIMA), y del Ministerio de Cultura, las Comunidades Autónomas y los Entes locales.

Seguidamente se formula una crítica del contenido del anteproyecto de la Ley del Patrimonio histórico-artístico y monumental, centrada en los siguientes aspectos:

- Definición de patrimonio.

- Organos administrativos encargados de la ejecución de la Ley.

- Función de la Administración central del Estado en relación con las Comunidades Autónomas.

- Formación de Catálogos e Inventarios.

- Conjuntos y núcleos urbanos y rurales.

- Los Planes Especiales.

- El carácter prohibitivo.

- Las afecciones del derecho de propiedad. 
También se aborda un comentario sobre la intención, los principios y los objetivos del anteproyecto de Ley de Rehabilitación del patrimonio arquitectónico.

Finalmente se centra el tema en un comentario de carácter histórico y de contenido teórico sobre las metas y las medidas de una política del suelo, desde un enfoque económico y participativo, exponiéndose los ejemplos de actuaciones seguidas en GoteburgBarrio de Haga.

También se aborda la consideración del patrimonio urbano como bien público, a través de la consideración del espacio urbano como mercancía, de la participación racional del ciudadano en la formación y uso de los espacios urbanos y de la función colectiva de los mismos.

\section{COMPETENCIAS DE LA ADMINISTRACION CENTRAL Y LOCAL EN LA PROTECCION DEL PATRIMONIO URBANO}

Por don Leandro Luque Sevilla, Técnico de Administración del Estado y Profesor adjunto de Derecho Administrativo de la Universidad de Granada.

Este conferenciante trata de hacer básicamente una recopilación de todos los aspectos en cuanto a concepto de patrimonio urbano y competencias atribuidas a las distintas Administraciones públicas, tratados en sesiones anteriores.

Dado el carácter coloquial de la sesión no se siguió un orden demasiado estricto, planteándose esencialmente las cuestiones suscitadas sobre conflictos de atribuciones entre la Administración del Estado y los Municipios.

Como conclusión se llegó a la necesidad de unificar y coordinar tales competencias a través de una legislación clara sobre la materia. 


\title{
VIII. EL CATALOGO URBANISTICO DE BIENES CULTURALES
}

\begin{abstract}
Por don Antonio Carceller Fernández, Profesor adjunto de Derecho Administrativo y Letrado de la Generalidad de Cataluña.
\end{abstract}

El Profesor Carceller desarrolla su exposición sobre un esquema facilitado previamente a los asistentes, que se articula en los siguientes capítulos:

1. Se refiere a las características objetivas de la propiedad monumental y a la necesidad de su protección; a la figura del Catálogo como instrumento de protección urbanística de los bienes culturales, centrándose en las situaciones en que los bienes catalogados son de propiedad particular, en cuya situación el peligro a evitar será el deseo de los propietarios de derribar el inmueble, cuyo mantenimiento suele ser gravoso e improductivo, para sustituirlo por construcciones de más elevado rendimiento.

2. Se centra el Profesor en el rango constitucional de las normas de protección, a los antecedentes que pueden encontrarse en otras Constituciones españolas, y más concretamente en el comentario del artículo 46 de la Constitución de 1978, según el cual "los poderes públicos garantizarán la conservación y promoverán el enriquecimiento del patrimonio histórico, cultural y artístico de los pueblos de España y de los bienes que lo integran, cualquiera que sea su régimen jurídico y su titularidad. La Ley penal sancionará los atentados contra este patrimonio".

3. Seguidamente pasa a comentarse la regulación de la figu: ra de los Catálogos en la legislación urbanística española, y más concretamente en los artículos 20 de la Ley del Suelo de 12 de mayo de 1956 y 25 del Texto refundido de 9 de abril de 1976, señalándose las diferencias de ambas normas, que se centran tan sólo en que la Ley de 1956 refería los Catálogos a todas las formas de protección contenidas en la propia Ley, mientras que la reforma ha referido estas figuras a la protección a que hacen relación los Planes Especiales. Parece ser que esta concreción quiere indicar una mayor interdependencia entre Plan Especial y Catálogo. 
4. Se analiza seguidamente el concepto de Catálogo, como relación, inventario, registro o lista, haciéndose una detallada referencia a los distintos textos legales de nuestro Ordenamiento jurídico que acogen tal figura para permitir el establecimiento de un régimen jurídico específico a determinados bienes; también se aborda la relación entre el Catálogo urbanístico como globalizador y totalizador y los Catálogos específicos de la Ley de 1933.

5. Se analiza también la naturaleza del Catálogo, definiéndose como documento urbanístico relacionado con el planeamiento, y a la vez como documento autónomo, no necesariamente subordinado a un Plan. También se estudia la naturaleza del acto de catalogación, considerándose como acto administrativo declarativo y no discrecional, sino reglado, en razón de los elementos objetivos concurrentes en el bien.

6. Como finalidad del Catálogo no cabe otra que la conservación y mejora de los bienes culturales incluidos en el mismo; se analiza el objeto del Catálogo, es decir, los bienes catalogables, centrándose el comentario en el equívoco carácter expansivo del concepto de monumentalidad, lo que a menudo lleva a la formación de Catálogos irreales; en todo caso, deberá exigirse la concurrencia de singulares valores o características específicas en los bienes catalogados. Como contenido formal se analiza la documentación en que puede concretarse el Catálogo.

7. Se trata brevemente del procedimiento de formación y aprobación de los Catálogos y especialmente de los temas referidos a posibles actos preparatorios, competencias, procedimiento, con especial referencia a la audiencia de los interesados y publicación del acto de aprobación y su alcance.

8. También se estudian los efectos de la aprobación de los Catálogos, y específicamente la imposibilidad de demolición y la restricción del aprovechamiento del bien catalogado. De ello se deriva la vinculación del bien a determinados usos o limitaciones, lo que incide sobre la situación jurídica de los propietarios. De ello se deduce la necesidad de compensación de estas modalidades de vinculaciones o limitaciones singulares.

9. $\quad$ Finalmente se analiza detalladamente el Registro público de bienes catalogados a que se refiere el artículo 87 del Reglamen- 
to de Planeamiento, iniciándose una interesante discusión sobre la posibilidad de suspensión de licencias por la tramitación de Catálogos, posibilidad que es admitida por una parte de los asistentes.

\section{EL PLAN ESPECIAL DE REFORMA INTERIOR DEL ALBAICIN (GRANADA)}

Por don Juan López Jaén, Arquitecto de la Gerencia Municipal de Urbanismo de Madrid, y con intervención de representantes de la Junta de Andalucía y Ayuntamiento de Granada.

El presente tema fue objeto de iniciación mediante una introducción teórica de Juan LóPEZ JAÉN sobre su experiencia en materia de protección de conjuntos urbanos de carácter histórico, exponiendo las dificultades que suelen hallarse tradicionalmente en este campo cuando se trata de reformar o rehabilitar barrios con: solidados.

El Plan de protección o de reforma interior ha venido siendo utilizado más como instrumento de destrucción que no como ins: trumento de conservación, es decir, no suele ser contemplado como instrumento para "hacer ciudad", sino como medio para aniquilarla. De ahí se deriva la necesidad de replantear el derecho urbanístico en los aspectos de nuestros cascos urbanos.

Se entra en el análisis del concepto de protección, definiéndolo como sostenimiento vivo y dinámico.

Se pasa después a comentar sobre diapositivas los aspectos concretos del Plan Especial de Reforma Interior del Barrio del Albaicín, iniciado con anterioridad a la reforma de la Ley del Suelo de 1975, describiéndose los estudios sectoriales realizados en cuanto a topografía, tipología edificatoria, usos, actividades, movilidad, niveles de renta y empleo, etc.

Finalmente se comenta detalladamente la solución aportada, que persigue los siguientes objetivos:

a) Mejora del nivel de dotaciones y servicios del barrio.

b) Mantenimiento de la población actualmente existente.

c) Incardinación del barrio en el sistema total de la ciudad. 
En una segunda parte se desarrolla una Mesa redonda con el Profesor LOPEZ JAÉN y varios representantes de la Junta de Andalucía y del Ayuntamiento de Granada sobre la problemática específica del urbanismo en la ciudad de Granada. Después de un amplio e interesante debate se llega a las siguientes conclusiones:

1..$^{\text {Existen }}$ graves problemas derivados del régimen transitorio. de suspensión de licencias en las zonas consolidadas donde se redacta planeamiento de reforma interior.

2. ${ }^{a} \quad$ Estos Planes deben pretender, ante todo, el mantenimiento en su residencia de los actuales habitantes del barrio, evitando su traslado como consecuencia del cambio de las circunstancias sociales.

3. Los problemas principales derivan de los aspectos financieros y de los costes de la reforma interior, frente a los cuales los. Ayuntamientos suelen verse desbordados por dificultades de gestión.

4. Las competencias interorgánicas suelen también dificultar el procedimiento de aprobación de estos Planes.

\section{LA LEGISLACION SOBRE EL PATRIMONIO CULTURAL}

Por el Profesor don Tomás-Ramón Fernández, Catedrático de Derecho Administrativo y Rector de la Universidad Nacional de Educación a Distancia.

Empieza esta charla con un comentario sobre la evolución del concepto de monumento, que ha pasado a abarcar no sólo las grandes obras, sino también las más modestas que hayan adquirido una relevancia cultural.

Se analizan después las características de la legislación del Patrimonio histórico-artístico, encontrándonos con la existencia de dos Ordenamientos:

- En primer lugar, la Ley de 1933, que afronta la protección del Patrimonio desde una perspectiva estática, basada en la idea de monumento como elemento aislado.

- En segundo lugar, el Ordenamiento urbanístico, que adopta una perspectiva dinámica, asumiendo las tradicionales técnicas de la 
policía administrativa (régimen de usos, facultad expropiatoria; órdenes, etc.), pero además aportando una idea de coordinación con el planeamiento globalizador, principalmente a través de la figura de los Planes Directores Territoriales de Coordinación.

Esta dualidad de Ordenamientos no se traduce en una mayor eficacia protectora.

Se formula a continuación una crítica de esta situación, afirmándose que a la Ley de 1933 le falta un marco general que contemple la aplicación de los criterios mantenidos respecto de los monumentos a los conjuntos históricos. También se hace notar la vaguedad de los preceptos que regulan los entornos, lo que dificulta el carácter reglado de la licencia. Finalmente, se hace notar la contradicción de criterios existente a menudo entre Planes Especiales vigentes y la concesión de licencias por parte de la Administración del Estado.

Asimismo se hace notar la falta de mecanismos de compensación del deber de conservar impuesto a los propietarios; se imponen obligaciones, pero en cambio no se dan los medios para poder:cumplir tales obligaciones, siendo ineficaces los meros estímulos fiscales.

Con respecto a la Ley del Suelo, se hace referencia a su artículo 87,3 , y al mecanismo de la reparcelación para compensar las cargas. Se afirma que la Ley del Suelo sigue siendo una Ley de ensanche que no contempla los mecanismos de actuación necesarios en el suelo urbano. Ello obliga a buscar nuevas técnicas de gestión en esta clase de suelo al objeto de rehabilitar y reactivar los centros urbanos. Este es el criterio imperante actualmente en España y en todo el mundo.

Se comentan las líneas de actuación en este campo señaladas por la Carta del Consejo de Europa de 1975 sobre Patrimonio Arquitectónico, así como por la Recomendación 880 del propio Consejo de Europa en el siguiente sentido:

- Rectificación de la legislación vigente, normalmente dispersa, sobre la base del apoyo en las técnicas del urbanismo más que en técnicas de protección puntual.

- Integración de la legislación sectorial del Patrimonio histórico-artístico en la legislación integral del urbanismo, a través del planeamiento y de las técnicas de control (licencias). 
- Potenciación de una auténtica política general de rehabilitación urbana, mediante ayudas financieras por lo menos iguales a las deparadas a las nuevas construcciones (viviendas oficiales).

Concretamente, en este campo, se propone la subvención a alquileres de viviendas restauradas, las bonificaciones fiscales y el régimen de préstamos a bajo interés.

\section{LAS LICENCIAS URBANISTICAS Y LA PROTECCION DEL PATRIMONIO CULTURAL}

Por don Eduardo Roca Roca, Profesor agregado de Derecho Administrativo de la Universidad de Granada y Director de la Semana de Estudios.

Se inicia la presente charla con una aproximación al concepto de Patrimonio cultural, analizándose a través de su objeto, sus sujetos y su régimen jurídico. El objeto será tanto un sector de bienes singulares y específicos, como los conjuntos monumentales, como sus entornos o ámbitos de influencia. Serán posibles sujetos titulares del Patrimonio cultural tanto la Administración como los particulares.

Por último, en cuanto al régimen jurídico aplicable, el Profesor Roca expresa su opinión de que se trata de uno solo, por existir un único Ordenamiento jurídico global. Para conocer el régimen aplicable considera el conferenciante que debe fijarse la atención en cuál sea la persona jurídica pública que debe gestionar o aplicar. el Ordenamiento jurídico. Si es la Administración del Estado aplicará las normas sobre Patrimonio histórico-artístico; si es la Administración local aplicará las normas de la legislación urbanística.

Se hace referencia al tradicional recelo del Estado a la hora de reconocer competencias en los Entes locales en esta materia, basado en la dudosa preparación de su personal, lo cual ha llevado a la centralización de tales competencias.

Se analiza también el fenómeno de la discordancia entre la ordenación urbanística y los criterios de intervención de la Administración central. 
En una segunda parte de la exposición se entra detalladamente en el estudio de la licencia como remoción de un límite para el ejercicio de un derecho que ya tenía el titular.

Relaciona el conferenciante este concepto con los procedimientos de otorgamiento de licencias contenidos, de una parte, en la Ley del Suelo, y de otra, en la legislación específica del Patrimonio histórico-artístico, exponiendo las distintas teorías formuladas sobre el tema. Así, para González PÉrez existirán dos licencias y dos procedimientos administrativos. Para el Profesor Roca se trata de un solo procedimiento en el que deben coordinarse las dos intervenciones:

Se analiza pormenorizadamente la jurisprudencia que trata de esta materia, conviniéndose en que la autorización de Bellas Artes parece ser como una condición de licencia municipal (intervènción ex post), si bien también puede entrar como condición previa.

Se distinguen los siguientes casos:

a) Solicitud de autorización previa del interesado ante la Dïrección General de Bellas Artes, con independencia de la licencia municipal.

b) Intervención de Bellas Artes por solicitud de la autoridad municipal en el expediente de concesión de la licencia.

c) Otorgamiento de licencia municipal, sin existencia de manifestación de voluntad de la Administración del Estado.

Se comenta también detalladamente la jurisprudencia que reconoce el carácter vinculante de las opiniones de la Dirección General de Bellas Artes, opinando el Profesor Roca que se trata de informes semivinculantes, ya que tan sólo vinculan cuando son desfavorables o negativos.

Finalmente, en animado coloquio, se discute el carácter de licencia previa o de dictamen que debe adjudicarse de la intervención de la Dirección General de Bellas Artes en el procedimiento, reconociéndose que participa de las características de ambas figuras. 


\section{FISCALIDAD Y PATRIMONIO ARTISTICO}

Profesor don Javier. Lasarte Alvares, Catedrático de Derecho Financiero de la Universidad de Granada.

La presente conferencia tiene por objeto reflejar la incidencia en la normativa tributaria de los bienes declarados monumentos histórico-artísticos, a tenor de lo expresado en la legislación protectora del Patrimonio histórico-artístico; dicha incidencia se refiere exclusivamente a las deducciones o exenciones tributarias de que gozan tales bienes tanto en el marco de la Hacienda estatal como en la local. Dichas deducciones o exenciones tributarias se recogen en tres impuestos, como son el de la Contribución Territorial Urbana, legislado en el Decreto 1251/1966, de 12 de mayo, y modificaciones posteriores, actualmente impuesto municipal en virtud de lo establecido en la Disposición transitoria primera de la Ley 44/1978, de 8 de septiembre, y los impuestos extraordinarios sobre el Patrimonio de las Personas Físicas a que hace referencia la Ley 50/1977, de 14 de noviembre, de Reforma Tributaria, desarrollada mediante Orden ministerial de 14 de enero de 1978, y sobre la Renta de las Personas Físicas, legislado por Ley $44 / 1978$, de 8 de septiembre.

a) El impuesto de la Contribución Territorial Urbana grava la renta producida por el bien calificado tributariamente de naturaleza urbana. En el artículo $8 .^{\circ}$, apartado 9), del texto regulador se reconoce a los bienes declarados expresa e individualmente monumentos histórico-artísticos la exención permanente de esta contribución, independientemente de la personalidad de su titular; ello significa que el bien objeto de la exención tributaria debe haber sido declarado expresa e individualmente monumento histórico-artístico, una vez resuelto el expediente incoado al efecto, conforme a lo previsto en la Ley reguladora del Patrimonio histórico-artístico y su Reglamento.

b) El impuesto extraordinario sobre el Patrimonio de las Personas Físicas se establece con carácter excepcional y transitorio y viene a gravar el patrimonio neto de las personas físicas, es decir, la propiedad de toda clase de bienes y la titularidad de derechos de 
contenido económico que se atribuyen a dichas personas. Al igual que el impuesto de la Contribución Territorial Urbana, los inmuebles urbanos declarados expresa e individualmente monumentos histórico-artísticos gozan de exención, tal y como señala el artículo $6^{\circ}$, apartado j), de la Ley de Reforma Tributaria de 14 de noviembre de 1977, sobre medidas urgentes de reforma fiscal, que es la que contempla el presente tributo, sumándose a dicha exención las obras de arte que cumplan los fines de difusión cultural fijados por los Ministerios de Hacienda y Cultura por vía reglamentaria.

c) El impuesto sobre la Renta de las Personas Físicas es un tributo que grava la renta de los sujetos pasivos del impuesto en función de sus circunstancias personales; centrándonos en sus bienes declarados monumentos histórico-artísticos, el hecho imponible consiste en la renta producida por éstos, o bien la aplicación de la renta obtenida en su conservación o salvaguarda. Contrariamente a lo establecido en los dos impuestos anteriores, aquí no existe exención del pago, y lo que sí se reconoce es una deducción de la cuota que resulte de la aplicación de la tarifa correspondiente a que hace referencia el artículo 28 de la propia Ley. Tal deducción es de un 15 por 100 en cuanto a la realización de obras de restauración de los inmuebles declarados monumentos histórico-artísticos o en las que se hagan para defensa del Patrimonio histórico-artístico nacional (artículo 29). En la legislación del Patrimonio histórico-artístico, y más concretamente en la Ley de 13 de mayo de 1933, reguladora del Patrimonio histórico-artístico (art. 30), y Ley de 22 de diciembre de 1955, sobre utilización de monumentos por sus propietarios (artículo $3 .^{\circ}$ ), se establece la exención de cargas fiscales, y en atención a las limitaciones impuestas en la primera de dichas leyes, para aquellos inmuebles así declarados, pues se consideran a efectos contributivos como monumentos públicos. Sin embargo, la exención, tal como se expresa en estos artículos, hoy en día puede considerarse superada, dudándose de su validez, en base a la normativa tributaria que posteriormente ha surgido y que aquí queda recogida, que contempla las deducciones y exenciones tributarias en razón a los monumentos histórico-artísticos, bajo un punto de vista más restrictivo.

En opinión del conferenciante, el hecho imponible del impuesto debería darse sólo cuando el bien patrimonial de que se trate aco- 
gido a la legislación protectora del Patrimonio histórico-artístico manifestara la capacidad de renta, como sería el caso de su utilización para operaciones financieras, enajenación, depósito, garantías, etcétera.

\section{CONCLUSIONES}

1..$^{2} \quad$ La protección y conservación del Patrimonio cultural está regulada por el Ordenamiento jurídico español sobre la base de dos grupos de normas: las recogidas en la legislación urbanística (Ley del Suelo y sus Reglamentos), y por remisión, la legislación de Régimen local, y en segundo lugar, las normas específicas sobre $\mathrm{Pa}$ trimonio histórico-artístico (Ley de 13 de mayo de 1933).

2. $\quad$ Esta dualidad no deriva en una mejor protección de los bienes contemplados, sino que produce confusionismo y una mayor complejidad en la resolución de los problemas abordados por la normativa.

3. ${ }^{\text {a }}$ Esta dualidad de normas conduce también a una dualidad de competencias asignadas a distintos órganos de la Administración del Estado y de la Administración local. Los criterios objetivos y soluciones aplicadas por tales órganos suelen ser distintas $\mathrm{y}$, por tanto, dificultan la protección.

4. ${ }^{2} \quad$ La legislación urbanística, más dinámica, debería ser integradora de los aspectos de protección y conservación del Patrimonio histórico-artístico, siendo la figura de los Planes Especiales la fórmula idónea para tales objetivos.

5. ${ }^{a}$ Los bienes a proteger deben definirse en razón de determinadas circunstancias objetivas.

6. ${ }^{\mathrm{a}}$ El planeamiento protector establecerá un régimen jurídico especial, que afectará al contenido del derecho de propiedad; nacerá así una propiedad de carácter especial, la cual debería ser objeto de regulación genérica.

7. ${ }^{\mathrm{a}} \quad$ La protección significa, por lo general, una limitación de las facultades del propietario $y$, ocasionalmente, un deber positivo de realizar determinadas actuaciones en el bien. Por ello, deberán arbitrarse desde la Administración las medidas de ayuda y compensación adecuadas, de forma que la carga económica de la protección recaiga sobre el verdadero beneficiario, es decir, sobre la comunidad. 
8. Debería definirse el régimen legal de las licencias en bienes objeto de especial protección, con el fin de compatibilizar la intervención de la Administración del Estado con las facultades de la Administración local.

9. Las operaciones de rehabilitación no tienen un apoyo económico ni un marco legal adecuados, topando la mayoría de las veces con los intereses de la población afectada. Es necesario un proceso de información previo, así como una evaluación real de los costes y de los medios de financiación correspondientes. 
REVISTA

$\mathrm{DE}$

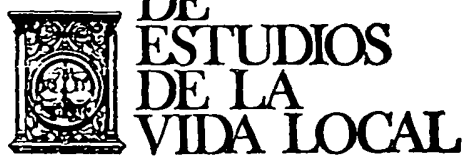

\section{ESTADISTICA}


REVL-1981, núm. 212. GRAU AVILA, SEBASTIAN. REGIMEN JURIDICO DE LA CONSERVACION,... REVL-1981, núm. 212. GRAU AVILA, SEBASTIAN. REGIMEN JURIDICO DE LA CONSERVACION,... 